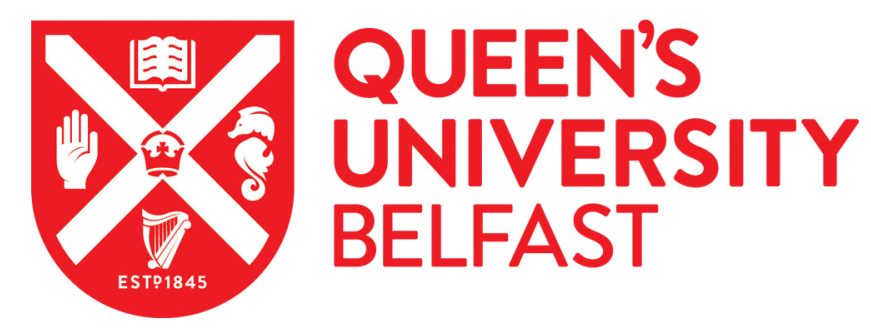

\title{
Posterior segment eye lesions: Prevalence and associations with ocular and systemic parameters: Results from the Gutenberg Health Study
}

Elbaz, H., Schulz, A., Ponto, K. A., Nickels, S., Pfeiffer, N., Mirshahi, A., \& Peto, T. (2019). Posterior segment eye lesions: Prevalence and associations with ocular and systemic parameters: Results from the Gutenberg Health Study. Graefe's Archive for Clinical and Experimental Ophthalmology, 1-9.

https://doi.org/10.1007/s00417-019-04416-w

\section{Published in:}

Graefe's Archive for Clinical and Experimental Ophthalmology

\section{Document Version:}

Peer reviewed version

Queen's University Belfast - Research Portal:

Link to publication record in Queen's University Belfast Research Portal

\section{Publisher rights}

Copyright 2019 Springer. This work is made available online in accordance with the publisher's policies. Please refer to any applicable terms of use of the publisher.

\section{General rights}

Copyright for the publications made accessible via the Queen's University Belfast Research Portal is retained by the author(s) and / or other copyright owners and it is a condition of accessing these publications that users recognise and abide by the legal requirements associated with these rights.

Take down policy

The Research Portal is Queen's institutional repository that provides access to Queen's research output. Every effort has been made to ensure that content in the Research Portal does not infringe any person's rights, or applicable UK laws. If you discover content in the

Research Portal that you believe breaches copyright or violates any law, please contact openaccess@qub.ac.uk. 


\section{Posterior segment eye lesions: Prevalence and associations with ocular and systemic parameters: Results from the Gutenberg Health Study}

Hisham Elbaz ${ }^{1,6,8}$, MD, FEBO, Andreas Schulz ${ }^{3}$, Katharina A. Ponto ${ }^{1,4}$, MD, FEBO,

Stefan Nickels ${ }^{1}, \mathrm{MD}$, Norbert Pfeiffer ${ }^{1}, \mathrm{MD}$, Alireza Mirshahi ${ }^{1,5}, \mathrm{MD}$, Tunde Peto ${ }^{2,7}$, MD, PhD.

1- Department of Ophthalmology, University Medical Center Mainz, Mainz, Germany

2- NIHR Biomedical Research Center at Moorfields Eye Hospital NHS Foundation Trust and UCL Institute of Ophthalmology, London, United Kingdom

3- Preventive Cardiology and Preventive Medicine / Center for Cardiology, University Medical Center Mainz, Mainz, Germany

4- Center for Thrombosis and Hemsostasis (CTH), University Medical Center Mainz, Mainz, Germany

5- Dardenne Eye Hospital, Bonn-Bad Godesberg, Germany

6- Department of Ophthalmology, University of Montreal, Quebec, Canada

7- Queen's University Belfast, Centre for Public Health, Northern Ireland, UK

8- Ophthalmology Department of the Philipps University of Marburg, Germany

Reprint requests:

Dr. med. Hisham Elbaz

c/o Prof. Dr. Norbert Pfeiffer

Department of Ophthalmology, University Medical CenterMainz, Langenbeckstr. 1, 55131 Mainz, Germany

Tel: +49 6131 17-7085, Fax: +49 $613117-6620$

Email: norbert.pfeiffer@unimedizin-mainz.de 


\section{Abstract:}

\section{Background:}

To estimate the prevalence of posterior segment eye lesions and to identify their ocular and systemic associations within the Gutenberg Health Study (GHS) in Germany.

\section{Methods:}

Assessment and grading of fundus images as well as physical examination and history taking were performed in the cross-sectional analysis of 15,010 subjects (aged 35-74 years) using standardised procedures to determine the prevalence and associations of various posterior segment eye lesions.

\section{$\underline{\text { Results: }}$}

Fundus photographs of both eyes were available for 12,782 (85.2\%; 50\% female) subjects. The prevalence weighted to the region of Mainz and Mainz-Bingen in Germany was for choroidal nevi $2.4 \%$, drusen of the optic nerve head $0.2 \%$, tilted discs $1.5 \%$, chorioretinal scars suggestive of toxoplasmosis $0.2 \%$, retinitis pigmentosa $0.04 \%$ and persistent hyaloid artery $0.02 \%$. Choroidal nevi were positively associated with a history of myocardial infarction $(O R=2.7,95 \%$ confidence interval $1.2-6.2, p$ value $=0.017)$. Tilted discs were positively associated with increased intraocular pressure (OR=1.09 per $\mathrm{mm} \mathrm{Hg}(1.02-1.16)$, $p=0.011)$ and negatively associated with smoking (OR $0.4(0.3-0.7), p=0.0022)$. Participants with tilted discs had a mean spherical equivalent of -3.6 dioptres (standard deviation 4.0) compared to -0.4 diopters (2.4) to those without. 


\section{Conclusion:}

Our Study is - to the best of our knowledge - the first to determine the prevalence of drusen of optic nerve head among Caucasians, to show a positive association between tilted discs and increased intraocular pressure and questions a possible link between choroidal nevi and myocardial infarction. It also showed that participants with tilted discs had a lower mean spherical equivalent than those without. 
Keywords:

ophthalmic epidemiology, retina, posterior segment, choroidal nevi, optic nerve drusen, retinitis pigmentosa, tilted discs, toxoplasmosis, posterior hyaloid artery, GHS 


\section{Introduction:}

The posterior segment of the eye is regarded as a mirror to the body, providing valuable information about the status of systemic diseases such as diabetes mellitus and hypertension. Knowledge of changes related to these conditions may help to understand systemic disease. Previous papers reported positive associations between diabetes mellitus and Synchisis syntillans ${ }^{1}$ and an association between tilted discs and myopia ${ }^{2}$, both might not have been found without analysing a large scale epidemiologic study.

In previous reports, the Gutenberg Health Study (GHS) has reported on the epidemiology of other medical and ophthalmological disorders in Germany. The prevalence of definite glaucoma, retinal venous occlusion and myelinated retinal nerve fibres within the GHS were determined as $1.44 \%^{3}, 0,4 \%^{4}$ and $0,4 \%^{5}$ respectively. The prevalence of diabetic retinopathy in screening-detected type 2 diabetes was $13 \%{ }^{6}$. In a smaller sample of 4,340 participants within the GHS; signs of early AMD (soft drusen, and pigmentary abnormalities) were detected in $11.9 \%$ of individuals of all age groups, whereas signs of late AMD (geographic atrophy or neovascular AMD) was found in $0.2 \%$ of individuals of all age groups. ${ }^{7}$

In this study, carried out within the framework of the GHS in Germany, we evaluated the prevalence of several posterior segment lesions, including choroidal nevi, drusen of the optic nerve head (visible on funduscopy), tilted discs, scars suggestive of toxoplasmosis, posterior hyaloid artery and retinitis pigmentosa as disease. We analysed their associations with ophthalmic parameters and systemic diseases. Our aim was to investigate these in Europe's most populous country and to compare our findings with existing data from other populations. 


\section{Subjects and Methods:}

\section{Study Population and instrumentation:}

The Gutenberg Health Study (GHS) is a population-based, prospective, observational cohort study in the Rhine-Main Region in Midwestern Germany with a total of 15,010 subjects aged between 35 and 74 years and follow-up after five years. The sample was drawn randomly from the local government's mandatory register. The cohort is stratified equally for sex and residence (urban and rural) per each decade of age. An important feature of the study design is the interdisciplinary combination of an ophthalmological examination, general and cardiovascular examinations, administration of various questionnaires, laboratory tests, and biobanking for proteomic and genetic analyses ${ }^{8-10}$.

The ophthalmic study design was described elsewhere ${ }^{10}$. In brief, all subjects underwent an ophthalmological examination including history of eye diseases, and ophthalmic tests such as autorefraction and visual acuity testing (Humphrey ${ }^{\circledR}$ Automated Refractor/Keratometer (HARK) 599 тм, Carl Zeiss Meditec AG, Jena, Germany). The mean spherical equivalent was calculated in diopters (sphere $+1 / 2$ cylinder) and was determined in all subjects. Intraocular pressure was measured by calculating the mean of 3 measurements within a $3-\mathrm{mmHg}$ range starting with the right eye using a noncontact tonometer and automatic air-puff control (Nidek NT-2000тм; Nidek, Co., Gamagori, Japan). Measurement of the central corneal thickness and keratometry measurement (Scheimpflug imaging with the Pachycam $^{\mathrm{TM}}$, Oculus, Wetzlar, Germany) were performed, as well as slitlamp biomicroscopy with undilated pupils (Haag-Streit BM 900®, Bern, Switzerland). The fundus images were taken with a non-mydriatic fundus camera (Visucam PRO NM ${ }^{\mathrm{TM}}$, Carl Zeiss AG, Jena, Germany) in a darkened room and with the 
pupil's natural width. Three photographs were taken of each eye, starting with the right eye: Two images $\left(30^{\circ}\right.$ and $45^{\circ}$ ) centred on the optic nerve, and $30^{\circ}$ centred on the macula and the midperipheral fundus.

All subjects enrolled in the Gutenberg health Study underwent a general medical examination and a cardiovascular risk factor analysis that investigated the various known risk factors such as smoking (current smoker vs. former or never smoker), obesity $\left(\mathrm{BMI}>=30 \mathrm{~kg} / \mathrm{m}^{2}\right)$, arterial hypertension (blood pressure $\geq 140 / 90$ as the mean of the second and third measurement after 8 and 11 minutes of rest, a physician's diagnosis, or intake of blood-pressure lowering medication), dyslipidaemia (diagnosed by a physician, or an LDL/HDL-ratio of $\geq 3.5$ ), diabetes mellitus (diagnosed by a physician, or known therapy, or $\mathrm{HbA} 1 \mathrm{c}>=6.5 \%$ ), history of cardiovascular diseases, family history of myocardial infarction, in addition to laboratory tests (Table 1). Migration status was defined according to the definition of the German microcensus ${ }^{11}$ The study protocol and study documents were approved by the local ethics committee of the Medical Chamber of RhinelandPalatinate, Germany (reference no. 837.020.07; original vote: 22.3 .2007 , latest update: 20.10.2015). According to the tenets of the Declaration of Helsinki, written informed consent was obtained from all subjects prior to entering the study.

\section{Image grading for the ocular posterior segment conditions:}

The grading of the fundus images took place at the Moorfields Eye Hospital Reading Center (MEHRC) and was performed by a trained German board certified ophthalmologist and grader (HE) and confirmed by a senior grader (TP). The following conditions were graded:

\section{1- Choroidal nevi:}


For the grading of choroidal nevi in our study, we used the same criteria for the definition of choroidal nevi as the Blue Mountains Eye Study, where a choroidal nevus was defined as an unequivocal pigmented slate blue or green grey choroidal lesion at least $500 \mu \mathrm{m}$ in diameter with borders that are detectable but not sharp. ${ }^{12}$ Care was taken not to include similar pathologies as melanocytoma, retinal hyperpigmentation, tigroid fundus, pigment scars, choroidal hemangiomas and osteomas. In the grading we examined the choroidal nevi for their shape (circular, oval, or irregular), position (temporal, nasal, macular), presence of drusen and the distance of the nearest part of the nevus to the optic disc margin, as some studies have suggested a relationship between nevus growth and the proximity of its posterior edge to the optic disc. ${ }^{12}$ We included only the measurements of the largest lesion in case of multiple nevi in the same eye.

Measurements of the choroidal nevi were performed using the same methods that were used in the Singapore Malay Eye Study (SiMES) namely Adobe photoshop CS5, with micrometer per pixel conversion calculated using $4500 \mu \mathrm{m}$ as the standard distance from the center of the optic disc to the center of the fovea. ${ }^{13}$

2- Drusen of the optic nerve head visible on funduscopy (DON):

DON are laminated acellular concretions within the optic nerve, which are visible only when present on the surface, however some can be situated deeper in the nerve. ${ }^{14}$ The grading and the detection of DON on the fundus images in our study is based on their appearance as crystalline yellowish white nodular lesions on the surface of the optic nerve head. 


\section{3- Tilted Discs:}

Tilted disc is a congenital anomaly of the optic nerve known to be associated with myopia ${ }^{15}$ and sometimes with stable visual field defects. As in previous studies, an optic disc was graded as tilted when the index of tilt was seen less than $0.75 .^{15,16}$ The index of tilt was used to assess the optic disc ovality using the ratio of minimum to maximum optic disc diameter. ${ }^{15}$ The definition of the angle of tilt was defined as the angle between the vertical meridian and the maximum optic disc diameter ${ }^{15}$.

4- Chorioretinal scars suggestive of Toxoplasmosis:

Chorioretinal scars suggestive of Toxoplasmosis were defined as well circumscribed pigmented scars with or withour satellite scars. Bilateral macular pigmented scars were suggestive of congenital lesions.

\section{5- Persistant hyaloid artery:}

Persistent hyaloid artery was defined either as a well perfused artery or its fibrous remnants emerging from the optic nerve head towards the lense that did not regress with the development of the vitreous body.

6- Retinitis pigmentosa:

Retinitis pigmentosa (RP) is considered to be one of the known causes of blindness during working life. ${ }^{17}$ The grading and the detection of RP in the fundus images was based on their typical fundus picture characterised by peripheral pigmented bone spicules representing the RPE hyperpigmentation, along with pale appearance of the optic nerve head and narrow retinal vessels. 


\section{Statistical analysis:}

All data underwent quality control by a central data management unit and were checked for completeness and correctness by predefined algorithms and quality plausibility controls. The prevalences are given as relative numbers in percent, weighted to the population of the regions of Mainz and Mainz-Bingen, Germany. Means were reported for systemic factors and ocular factors (for example: central corneal thickness and spherical equivalent). With logistic regression models (Odds Ratio, 95\% confidence intervals and $p$-values) we evaluated whether the more frequent posterior segment lesions with sufficient data as choroidal naevi and tilted discs were associated with age, sex, intraocular pressure, as well as additional models including cardiovascular risk factors and comorbidities. Due to the exploratory character of this study, we did not adjust for multiple testing. P-values are given for descriptive reasons only and should be interpreted with caution, regarding the number of tests performed. The statistical analysis was performed using R version 3.1.1 (R Core Team (2014). R: A language and environment for statistical computing. R Foundation for Statistical Computing, Vienna, Austria. URL http://www.R-project.org/).

\section{Results:}

Fundus photographs of both eyes were available in 12,782 GHS subjects (85.2 $\%)$, of at least one one eye in $12,788(85.2 \%)$ of 15,010 GHS subjects. The study cohort included 6,400 (50\%) men and 6,388 (50\%) women. The mean age in the whole cohort was $54.9 \pm 11.1$ years, $54.7 \pm 11.1$ and $55.1 \pm 11.1$ years in women and men, respectively. 90 subjects $(0.7 \%$ of the 12,788$)$ were non-Caucasians (either migrating or having one of the parents migrating from a country of a nonCaucasian population). The mean BMI was $27.3 \pm 5.0 \mathrm{~kg} / \mathrm{m}^{2}\left(26.8 \pm 5.6 \mathrm{~kg} / \mathrm{m}^{2}\right.$ in 
women and $27.8 \pm 4.3 \mathrm{~kg} / \mathrm{m}^{2}$ in men). The mean intraocular pressure, spherical equivalent and central corneal thickness in this cohort is calculated as $14.2 \pm 2.7$ $\mathrm{mmHg},-0.4 \pm 2.4$ dioptres and $554 \pm 35 \mu \mathrm{m}$, respectively (Table 2 ).

\section{1- Choroidal nevi:}

Bilateral grading was available in $11,473(89.7 \%)$ of the available fundus photographs of the 12,788 GHS subjects. Choroidal nevi were seen in at least one eye of $287(2.5 \%)$ participants. Information for both eyes was available in 270 of the 287 subjects. Of these, $12(4.4 \%)$ had bilateral lesions, whereas 258 subjects $(95.6 \%)$ had only involvement of one eye. Comparing right to left eyes in the participants with unilateral involvement 144 (55.8\%) right and $114(44.2 \%)$ left eyes were involved, respectively. The mean age of those with choroidal nevi was $55.7 \pm 11.2$ years versus $54.1 \pm 10.9$ years in those without; $50.3 \%$ of all subjects with choroidal nevi were woman. Mean best-corrected logMAR visual acuity was $0.1 \pm 0.2$ in those with naevus versus $0.1 \pm 0.1$ in those without.

The median nevus diameter was $1.8 \mathrm{~mm}\left(5^{\text {th }}\right.$ percentile $1.0 \mathrm{~mm}, 95^{\text {th }}$ percentile 5.1 $\mathrm{mm}$ ). The median distance of the posterior margin of the nevus to the optic disc was $2.4 \mathrm{~mm}\left(5^{\text {th }}\right.$ percentile $0 \mathrm{~mm}, 95^{\text {th }}$ percentile $5.6 \mathrm{~mm}$ ) and median surface area was $1.9 \mathrm{~mm}^{2}\left(5^{\text {th }}\right.$ percentile $0.6 \mathrm{~mm}^{2}, 95^{\text {th }}$ percentile $\left.6.8 \mathrm{~mm}^{2}\right)$. Regarding the shape of the nevi, $2.2 \%$ of the nevi were of rounded shape, $46.5 \%$ showed an ovoid shape, and $51.3 \%$ were irregular in shape. $84.0 \%$ of the choroidal nevi were dark and pigmented and $16 \%$ were faint and depigmented. Drusen were found on the surface of $26.7 \%$ of the nevi, but none had subretinal fluid or orange pigment. Choroidal nevi lesions were mostly located in the temporal area not including the 
macula $(43.7 \%)$, followed by the nasal area $(28.1 \%)$, the macular area $(17.4 \%)$ and the rest in the peripapillary area (10.8\%).

The unweighted prevalence of choroidal nevi was calculated as $2.5 \%$, whereas the prevalence weighted to the region of Mainz and Mainz-Bingen was $2.4 \%$.

In the logistic regression model, there were no associations found between choroidal nevi and age, sex, intraocular pressure, and central corneal thickness (Table 3). However, most interestingly, amongst the cardiovascular risk factors and events, choroidal nevi were positively associated with a history of myocardial infarction $(\mathrm{OR}=2.7, \mathrm{p}$ value $=0.017,95 \% \mathrm{Cl} 1.2-6.2)$

2- Drusen of the optic nerve head visible on funduscopy:

Bilateral grading was available in $12,746(99.7 \%)$ of the available fundus photographs of the 12,788 GHS subjects. Drusen of the optic nerve head (DON) were seen in $22(0.17 \%)$ participants. Of these, $14(63.6 \%)$ had bilateral lesions, whereas in $8(36.4 \%)$ only one eye was involved, of these $6(75 \%)$ were right eyes. The mean age of the subjects having DON was $58.9 \pm 9.81$ years versus $54.9 \pm 11.1$ years in subjects without DON; and exactly $50 \%$ (11 subjects) were women. Mean best-corrected logMAR VA was $0.2 \pm 0.3$ in those with OND versus $0.1 \pm 0.2$ in those without. The mean spherical equivalent for eyes with DON was $+0.4 \pm 2.2$ dioptres and $-0.4 \pm 2.4$ dioptres for those without. Both the unweighted and the prevalence weighted to the region of Mainz and Mainz-Bingen were both $0.2 \%$.

\section{3- Tilted discs:}

Bilateral grading was available in $12,746(99.7 \%)$ of the available fundus photographs of the 12,788 GHS subjects. Tilted discs were found in $192(1.51 \%)$ 
participants, from those,bilateral readings were available for 189 participants. Bilaterality was detected in 95 (50.3\%); slightly more tilted discs affected the right eye $52(55.3 \%)$ of those with uniocular involvement. The mean age of the subjects with tilted discs was $55.2 \pm 10.8$ years versus $54.9 \pm 11.1$ years for those without. Slightly more woman were affected (100 subjects, $52.9 \%$ of cases). The mean best-corrected logMAR visual acuity was slightly worse $(0.2 \pm 0.3)$ in those with tilted discs versus $0.1 \pm 0.2$ in those without. Situs inversus of the retinal vessels was detected in 52 subjects (27.5\%). Unweighted as well as prevalence weighted to region of Mainz and Mainz-Bingen were calculated as $1.5 \%$.

The mean spherical equivalent for eyes with tilted discs was $-3.6 \pm 4.0$ dioptres and $-0.4 \pm 2.4$ dioptres for those without; while there was no difference in those with and without situs inversus. Table 4 illusrtrates the mean spherical equivalent in different posterior segment lesions including tilted discs. In the logistic regression models, no associations of tilted discs with age, sex and central corneal thickness were found (Table 5). However tilted discs were weakly associated with increased intraocular pressure $(\mathrm{OR}=1.1(1.02-1.16), \mathrm{p}$ value $=0.011)$. A negative association with smoking (OR $0.4(0.3-0.7), p=0.0022)$ was found.

4- Chorioretinal scars suggestive of Toxoplasmosis:

Bilateral grading was available in 11,461 (89.6\%) of the available fundus photographs of the 12,788 GHS subjects. Chorioretinal scars suggestive of Toxoplasmosis were found in $22(0.19 \%)$ participants; 20 had grading for both eyes with only 3 having had bilateral lesions. There was an even distribution between right and left eyes (8 right and 9 left eyes). The mean age of the subjects with chorioretinal scars suggestive of Toxoplasmosis was $56.8 \pm 11.0$ years versus $54.1 \pm 10.9$ years in those without; 7 subjects were women. Mean best-corrected 
logMAR visual acuity was $0.2 \pm 0.3$ in involved subjects versus $0.1 \pm 0.1$ in uninvolved subjects. Both the unweighted and the prevalence weighted to the region of Mainz and Mainz-Bingen were $0.2 \%$.

5- Other rare conditions:

Retitinis pigmentosa was bilaterally found in 5 subjects $(1: 2558)$ and persistent hyaloid artery was unilaterally seen in 3 subjects $(1: 4,256)$.

\section{Discussion:}

Our study is the first to deliver prevalence data for some rare conditions of the posteror pole in midwestern Europe. It analyses their associations with other ocular and systemic findings and compares the results with prevalence data from other population based studies in other areas of the world.

We found that tilted discs are positively associated with increased intraocular pressure and myopia. Another intriguing finding from our study is a questionable positive association of choroidal nevi and a history of myocardial infarction. The discussion will concentrate on the individual pathologies in more details.

\section{1- Choroidal nevi:}

In this study we found a statistically positive association of choroidal nevi with a history of myocardial infarction (logistic regression models; OR= $2.7(\mathrm{Cl}$ 95\% 1.26.2), $\mathrm{p}$ value $=0.017)$. Interestingly, a positive association between choroidal nevi and high levels of C-reactive proteins was previously documented in MESA ${ }^{18}$. C- 
reactive proteins are inflammatory markers that rise in both, inflammatory conditions and tissue damage such as myocardial infarction. These two associations call for the need of more studies that explore any potential connection between melanocytic lesions and conditions of tissue damage as in myocardial infarction; the result of which may possibly identify a link between choroidal nevi and the risk of developing myocardial infarction.

The $2.5 \%$ prevalence of choroidal nevi in this study was found lower than the $6.5 \%$ prevalence reported in the Blue Mountains Eye Study (BMES) ${ }^{12}$, the prevalence among white US-americans in the National Health and Nutrition Examination Survey $(5.6 \%)^{19}$, and the $2.9 \%$ prevalence among adult Chinese ${ }^{20}$ whilst higher than the estimated $1.4 \%$ prevalence among Asians in the Singapore Malay Eye Study (SiMES) ${ }^{13}$ and the $0.3 \%$ prevalence among adult Indians ${ }^{21}$. The Multi-Ethnic Study of Atherosclerosis (MESA) estimated the overall prevalence of choroidal nevi in its subjects to be $2.1 \%$, with prevalences higher in whites $(4.1 \%)$ than individuals of Afro-Carribean origin (0.7\%), Hispanics (1.2\%), and Chinese $(0.4 \%) .^{18}$

According to the Collaborative Ocular Melanoma Study (COMS), the size of the choroidal nevi and the absence of overlying drusen are considered part of the indicators of the potential transformation to choroidal melanoma ${ }^{22}$. The median diameter of choroidal nevi in our study is $1.8 \mathrm{~mm}, \mathrm{BMES}^{12}, \mathrm{SiMES}^{13}$ and the adult Chinese $^{20}$ study recorded smaller averages $(1.3 \mathrm{~mm} \cdot 1.3 \mathrm{~mm}$ and $1.5 \pm 0.7 \mathrm{~mm}$, respectively) while slightly larger nevi were found in adults Indians ${ }^{21}$ and MESA ${ }^{18}$ (2.2 $\pm 0.7 \mathrm{~mm}$ and $2.04 \mathrm{~mm}$, respectively).

Our findings of Drusen in the nevi in $26.7 \%$ is within the reported range of $20 \%$ in SiMES $^{13}, 13.1 \%$ in adult Chinese ${ }^{20}, 64 \%$ in adult Indians ${ }^{21}$, and $25 \%$ in MESA ${ }^{18}$. 
The only study that reported a vastly different result of $98 \%$ Drusen covergage is the BMES $^{12}$, but its study population range was older and that might explain such a difference.

The median surface area of choroidal nevi in our study is $1.9 \mathrm{~mm}^{2}$ and, thus, larger than that recorded in SIMES $\left(1.5 \pm 1.1 \mathrm{~mm}^{2},{ }^{13}\right)$, similar to $1.8 \pm 1.9 \mathrm{~mm}^{2}$ in adults Chinese $\mathrm{e}^{20}$, and smaller than in $2.7 \pm 1.2 \mathrm{~mm}^{2}$ in adult Indians ${ }^{21}$ and $5.3 \pm 1.2$ $\mathrm{mm}^{2}$ in MESA ${ }^{18}$

The median distance from the optic nerve head in our study was $2.4 \mathrm{~mm}$, about half the distance measured in adult Indians ${ }^{21}$ with an average of $4.53 \pm 0.22 \mathrm{~mm}$. In SIMES the margin of $34 \%$ of the nevi was within 2 disc diameters (DD) of the optic disc $^{13}$, while in adult Chinese $64.6 \%$ were within 2 disc diameters ${ }^{20}$, similar to the $72 \%$ that were reported by MESA. ${ }^{18}$

\section{2- Drusen of the optic nerve head visible on funduscopy:}

The $0.2 \%$ prevalence of drusen of the optic nerve head visible on funduscopy in this study was equal to the prevalence recorded in an adult Chinese population ${ }^{23}$. Both studies were comparable in terms of the age group of the study sample as the Beijing Eye Study also included individuals aged $\geq 40$ years. $^{23}$

\section{3- Tilted Discs:}

The prevalence of tilted discs in this study was $1.5 \%$. We found positive associations with myopia (mean spherical equivalent of individuals having tilted discs was $-3.6 \pm 4.0$ diopters) and increased intraocular pressure (logistic regression: $\mathrm{OR}=1.089,95 \% \mathrm{Cl} 1.02-1.16, \mathrm{p}$ value=0.011). $\mathrm{A}$ similar prevalence of 
tilted discs was reported in the BMES (1.6\%), but the Beijing Eye Study (BES) reported only about $1 / 3^{\text {rd }}$ of this prevalence $(0.5 \%)^{2}$. Similar to our study, positive associations with myopia in both of the above mentioned studies were established. However, our study is the first to show a positive association of tilted discs with increased intraocular pressure and hence a potentially positive link to glaucoma.

\section{4- Retinitis Pigmentosa:}

The 1:2558 prevalence of RP in this study was higher than the 1:4000 prevalence documented in the Beijing Eye Public Health care Project in North China ${ }^{24}$, and lower than the 1:750 prevalence value documented in the Central India Eye and Medical Study in rural India which attributed its relatively high RP prevalence rate to the high rates of consanguinity in rural India ${ }^{25}$. A lower RP prevalence was reported in the Danish Nationwide RP Registry $\left(1: 3026^{17}\right)$, while both Maine, USA and Birmingham, UK reported about half that of ours $\left(1: 4762^{26}\right.$ and $1: 4869^{27}$ respectively). These data need to be interpreted with caution as the numbers are small and therefore the estimates might be fairly unstable.

\section{5- Chorioretinal scars suggestive of Toxoplasmosis and persistent hyaloid artery:}

There are no previous data or prevalence values available from other population based studies for comparison.

\section{Strengths and limitations of the study:}

The strength of GHS comes from being a large, well studied and carefully characterised European cohort that allows prevalence estimates for several 
posterior segment lesions to be established and also allows for examination of possible associations with other ocular and, due to its interdisciplinary nature, systemic conditions. The GHS uses standardised operating procedures for its tests and investigations as well a standardised grading system for fundus images, therefore the reliability of the data is excellent.

Of course, there are limitations to our study. Peripheral pathologies, such as nevi and RP might have been underestimated as no widefield images were available. There was no ultrasonographic examination of the optic nerve head and so the prevalence of optic disc drusen buried deep within the optic nerve could not be found. In addition, there is a chance that patients with severe visual impairment might not have been able to participate in the GHS, and this selection bias could have influenced our prevalence estimates. Despite these limitations, the results of the GHS add to the general knowledge in ophthalmology and raises some aspects that might warrant further investigation. 


\section{Compliance with Ethical Standards:}

Funding: The Gutenberg Health Study is funded through the government of Rhineland-Palatinate (,Stiftung RheinlandPfalz für Innovation“, contract AZ 961386261/733), the research programs "Wissenschafft Zukunft" and "Center for Translational Vascular Biology (CTVB)" of the Johannes Gutenberg-University of Mainz, and its contract with Boehringer Ingelheim,PHILIPS Medical Systems, and Novartis Pharma $\mathrm{GmbH}$ including unrestricted grants for the Gutenberg Health Study. Katharina A. Ponto is funded by the Federal Ministry of Education and Research (BMBF 01E01503). T Peto was funded from the NIHR BMRC at Moorfields Eye Hospital NHS Foundation Trust and UCL Institute of Ophthalmology, London, UK.

Conflict of Interest: All authors declare that they have no conflict of interest.

Ethical approval: This article does not contain any studies with animals performed by any of the authors. All procedures performed in studies involving human participants were in accordance with the ethical standards of the institutional and/or national research committee and with the 1964 Helsinki declaration and its later amendments or comparable ethical standards. Informed consent was obtained from all individual participants included in the study. The study protocol and study documents were approved by the local ethics committee of the Medical Chamber of Rhineland-Palatinate, Germany (reference no. 837.020.07). 


\section{References:}

1. Bergren R, Brown G, Duker J. (1991) Prevalence and association of asteroid hyalosis with systemic diseases. Am J Ophthalmol.;111:289-293. doi:10.1016/S0002-9394(14)72311-6

2. You QS, Xu L, Jonas JB. (2008) Tilted optic discs: The Beijing Eye Study. Eye (Lond).;22(5):728-729. doi:10.1038/eye.2008.87

3. Höhn R, Nickels S, Schuster AK, et al. (2018) Prevalence of glaucoma in Germany: results from the Gutenberg Health Study. Graefe's Arch Clin Exp Ophthalmol.;256(9):1695-1702. doi:10.1007/s00417-018-4011-z

4. Ponto, K A, Elbaz H. PT, Wild PS. (2015) Prevalence and risk factors of retinal vein occlusion: the Gutenberg Health Study. Journal of Thrombosis and Haemostasis.;13(7):1254-1263. doi:10.1111/jth.12982

5. Elbaz H, Peto T, Butsch C, et al. (2016) Prevalence and associations of myelinated retinal nerve fibers: Results from the population-based gutenberg health study. Retina.;36(12):2364-2370. doi:10.1097/IAE.0000000000001093

6. Ponto KA, Koenig J, Peto T, et al. (2016) Prevalence of diabetic retinopathy in screening-detected diabetes mellitus: results from the Gutenberg Health Study (GHS). Diabetologia.;59(9):1913-1919. doi:10.1007/s00125-016-4013-5

7. Korb CA, Kottler UB, Wolfram C, et al. (2014) Prevalence of age-related macular degeneration in a large European cohort: Results from the populationbased Gutenberg Health Study. Graefe's Arch Clin Exp Ophthalmol.;252(9):14031411. doi:10.1007/s00417-014-2591-9

8. Mirshahi a, Ponto K a, Höhn R, Wild PS, Pfeiffer N. (2013)

[Ophthalmological aspects of the Gutenberg Health Study (GHS): an interdisciplinary prospective population-based cohort study].

Ophthalmologe.;110(3):210-217. doi:10.1007/s00347-012-2666-0

9. Wild PS, Zeller T, Beutel M, et al. (2012) [The Gutenberg Health Study]. Bundesgesundheitsblatt Gesundheitsforschung Gesundheitsschutz.;55(6-7):824829. doi:10.1007/s00103-012-1502-7

10. Höhn R, Kottler U, Peto T, et al. (2015) The Ophthalmic Branch of the Gutenberg Health Study: Study Design, Cohort Profile and Self-Reported Diseases. PLoS One.;10(3):e0120476. doi:10.1371/journal.pone.0120476

11. Beutel ME, Jünger C, Klein EM, et al. (2016) Depression, anxiety and suicidal ideation among $1 \mathrm{st}$ and 2 nd generation migrants - results from the Gutenberg health study. BMC Psychiatry.;16(1):1-10. doi:10.1186/s12888-0160995-2 
12. Sumich $P$, Mitchell $P$, Wang JJ. (1998) Choroidal Nevi in a White Population. The Blue Mountains Eye Study. ARCH OPHTHALMOL.;116:645-650.

13. $\mathrm{Ng} \mathrm{CH}$, Wang JJ, Mitchell P, Amirul Islam FM, Wong TY. (2009) Prevalence and characteristics of choroidal nevi in an Asian vs white population. Arch Ophthalmol.;127(3):314-319. doi:10.1001/archophthalmol.2008.625

14. Thurtell MJ, Biousse V, Bruce BB, Newman NJ. (2012) Optic nerve head drusen in black patients. J Neuroophthalmol.;32(1):13-16.

doi:10.1097/WNO.0b013e3182268655

15. AS H, GW T, Chan $Y$, al et. (2009) Population prevalence of tilted and torted optic discs among an adult chinese population in singapore: The tanjong pagar study. Arch Ophthalmol.;127(7):894-899.

http://dx.doi.org/10.1001/archophthalmol.2009.134.

16. Jonas JB, Kling F, Gründler AE. (1997) Optic Disc Shape, Corneal Astigmatism, and Amblyopia. Ophthalmology.;104(11):1934-1937. doi:10.1016/S0161-6420(97)30004-9

17. Haim M. (2002) The epidemiology of retinitis pigmentosa in Denmark. Acta Ophthalmol Scand.:1-34. http://onlinelibrary.wiley.com/doi/10.1046/j.13953907.2002.00001.x/full. Accessed November 11, 2014.

18. Greenstein M, Myers C, Meuer S. (2011) Prevalence and characteristics of choroidal nevi: the multi-ethnic study of atherosclerosis.

Ophthalmology.;118(12):2468-2473. doi:10.1016/j.ophtha.2011.05.007

19. Qiu M, Shields CL. (2015) Choroidal Nevus in the United States Adult Population Racial Disparities and Associated Factors in the National Health and Nutrition Examination Survey. Ophthalmology.;122(10):2071-2083. doi:10.1016/j.ophtha.2015.06.008

20. Jonas JB, You QS, Xu L, Wang YX. (2008) Choroidal nevi in adult chinese. Ophthalmology.;115(6):1102-1102.e1. doi:10.1016/j.ophtha.2007.12.022

21. Nangia V, Jonas JB, Agarwal S, Khare A, Lambat S, Panda-Jonas S. (2012) Choroidal nevi in adult Indians: The Central India Eye and Medical Study. Br J Ophthalmol.;96(11):1443-1444. doi:10.1136/bjophthalmol-2012-302164

22. (1997) Factors predictive of growth and treatment of small choroidal melanoma: Coms report no. 5. Arch Ophthalmol.;115(12):1537-1544. http://dx.doi.org/10.1001/archopht.1997.01100160707007.

23. You QS, Xu L, Wang YX, Jonas JB. (2009) Prevalence of optic disc drusen in an adult Chinese population: the Beijing Eye Study. Acta Ophthalmol. 2009;87(2):227-228. doi:10.1111/j.1755-3768.2008.01211.x 
24. You QS, Xu L, Wang YX, et al. (2013) Prevalence of retinitis pigmentosa in North China: the Beijing Eye Public Health Care Project. Acta Ophthalmol.;91(6):e499-500. doi:10.1111/aos.12163

25. Nangia V, Jonas JB, Khare A, Sinha A. (2012) Prevalence of retinitis pigmentosa in India: the Central India Eye and Medical Study. Acta Ophthalmol. ;90(8):e649-50. doi:10.1111/j.1755-3768.2012.02396.x

26. Clareann B, Berson EL, Bromley WC, Hayes RP, Roderick TH. (1984) Prevalence of Retinitis pigmentosa in Maine. Am J Ophthalmol. ;97:357-365.

27. Bundey, S., \& Crews, S. J. (1984). A study of retinitis pigmentosa in the City of Birmingham. I Prevalence. Journal of medical genetics, 21(6), 417-420. doi:10.1136/jmg.21.6.417

\section{Tables:}

Table 1: Sample characteristics of the German population-based Gutenberg Health Study (GHS), 2007-2012, weighted to the region of Mainz and Mainz-Bingen.

Table 2: Prevalences of posterior segment lesions (absolute and weighted for the region of Mainz and Mainz-Bingen) in the German population-based Gutenberg Health Study (GHS), 2007-2012.

Table 3: Associations of choroidal nevi and drusen of the optic nerve head visible on funduscopy with ocular parameters and cardiovascular risk factors in the German population-based Gutenberg Health Study (GHS), 2007-2012.

Table 4: Mean spherical equivalent in different posterior segment leisons in the German population-based Gutenberg Health Study (GHS), 2007-2012.

Table 5: Associations of tilted discs with ocular parameters and cardiovascular risk factors in the German population-based Gutenberg Health Study (GHS), 2007-2012. 
Table 1: Sample characteristics of the German population-based Gutenberg Health Study (GHS), 2007-2012, weighted to the region of Mainz and Mainz-Bingen.

\begin{tabular}{|c|c|c|c|}
\hline & All (12803.62) & Men (6313.64) & Women (6484.99) \\
\hline Sex (Women) & $50.6 \%(6485.0)$ & $0 \%(0)$ & $100.0 \%(6485.0)$ \\
\hline Age [years] & $52.5 \pm 11.0$ & $52.2 \pm 10.9$ & $52.8 \pm 11.1$ \\
\hline Body mass index $\left[\mathrm{kg} / \mathrm{m}^{2}\right]$ & $27.2 \pm 5.0$ & $27.7 \pm 4.3$ & $26.7 \pm 5.6$ \\
\hline Systolic blood pressure [mmHg] & $130 \pm 17$ & $133 \pm 16$ & $127 \pm 18$ \\
\hline Diastolic blood pressure [mmHg] & $82.4 \pm 9.5$ & $84.0 \pm 9.4$ & $80.9 \pm 9.4$ \\
\hline \multicolumn{4}{|l|}{ Classical cardiovascular risk factors: } \\
\hline Hypertension & $45.0 \%(5755.9)$ & $49.2 \%(3106.7)$ & $40.9 \%(2649.3)$ \\
\hline Diabetes & $6.1 \%(780.1)$ & $7.5 \%(472.2)$ & $4.8 \%(307.9)$ \\
\hline Dyslipidemia & $28.3 \%(3618.7)$ & $36.2 \%(2281.4)$ & $20.7 \%(1337.3)$ \\
\hline Obesity & $24.2 \%(3095.5)$ & $25.3 \%(1595.8)$ & $23.1 \%(1499.7)$ \\
\hline Smoking & $21.0 \%(2682.5)$ & $22.8 \%(1437.3)$ & $19.2 \%(1245.2)$ \\
\hline Family history of Myocardial infarction & $16.6 \%(2121.5)$ & $15.4 \%(972.5)$ & $17.7 \%(1149.0)$ \\
\hline \multicolumn{4}{|l|}{ Comorbidities: } \\
\hline Myocardial infarction (MI) & $2.3 \%(294.9)$ & $3.5 \%(220.6)$ & $1.1 \%(74.3)$ \\
\hline Stroke & $1.5 \%(193.6)$ & $1.9 \%(117.6)$ & $1.2 \%(76.0)$ \\
\hline Atrial fibrillation (AF) & $2.2 \%(280.9)$ & $2.9 \%(183.2)$ & $1.5 \%(97.7)$ \\
\hline Congestive Heart failure (CHF) & $1.1 \%(143.1)$ & $1.1 \%(70.8)$ & $1.1 \%(72.3)$ \\
\hline
\end{tabular}




\begin{tabular}{|l|l|l|l|}
\hline Coronary artery disease (CAD) & $3.4 \%(431.1)$ & $5.1 \%(319.5)$ & $1.7 \%(111.6)$ \\
\hline $\begin{array}{l}\text { Chronic obstructive pulmonary disease } \\
\text { (COPD) }\end{array}$ & $4.7 \%(603.1)$ & $4.1 \%(257.2)$ & $5.3 \%(345.9)$ \\
\hline Chronic renal diseases (CKD) & $1.0 \%(128.8)$ & $1.0 \%(63.7)$ & $1.0 \%(65.2)$ \\
\hline Chronic liver diseases (CLD) & $0.7 \%(90.4)$ & $0.6 \%(37.7)$ & $0.8 \%(52.7)$ \\
\hline Ocular parameters: & $14.2 \pm 2.7$ & $14.3 \pm 2.8$ & $14.1 \pm 2.6$ \\
\hline Intraocular pressure [mmHg] & $554 \pm 35$ & $556 \pm 35$ & $552 \pm 35$ \\
\hline Central corneal thickness [ $\mu \mathrm{mm}]$ & $-0.6 \pm 2.4$ & $-0.6 \pm 2.3$ & $-0.5 \pm 2.5$ \\
\hline Spherical equivalent [dioptres] & $0.1 \pm 0.2$ & $0.1 \pm 0.2$ & $0.1 \pm 0.1$ \\
\hline Visual acuity [LogMar] & $1.8 \%(233.6)$ & $1.7 \%(109.8)$ & $1.9 \%(123.9)$ \\
\hline self-reported glaucoma & & & \\
\hline
\end{tabular}


Table 3: Associations of choroidal nevi and drusen of the optic nerve head visible on funduscopy with ocular parameters and cardiovascular risk factors in the German population-based Gutenberg Health Study (GHS), 2007-2012.

\begin{tabular}{|c|c|c|c|c|}
\hline & \multicolumn{2}{|c|}{ Choroidal nevi } & \multicolumn{2}{|c|}{$\begin{array}{l}\text { Drusen of the optic } \\
\text { nerve head visible on } \\
\text { funduscopy }\end{array}$} \\
\hline & OR (95\%CI) & p-value & OR $(95 \% C I)$ & p-value \\
\hline Sex (woman) & $0.9(0.7-1.2)$ & 0.64 & $0.9(0.7-1.1)$ & 0.20 \\
\hline Age (10 y) & $1.1(1.0-1.3)$ & 0.18 & $1.1(1.0-1.2)$ & 0.02 \\
\hline Glaucoma * & $3.1(0.4-24.1)$ & 0.3 & $1.5(0.2-11.6)$ & 0.70 \\
\hline IOP (mmHg) & $0.1(0.9-1.0)$ & 0.48 & $1.0(1.0-1.1)$ & 0.26 \\
\hline $\mathrm{CCT}(\mu \mathrm{m})$ & $1.0(1.0-1.0)$ & 0.95 & $1.0(1.0-1.0)$ & 0.94 \\
\hline Hypertension & $0.9(0.7-1.3)$ & 0.7 & $1.0(0.8-1.2)$ & 0.75 \\
\hline Diabetes mellitus & $1.3(0.8-2.2)$ & 0.3 & $1.5(1.1-2.1)$ & 0.03 \\
\hline Dyslipidemia & $1.1(0.8-1.4)$ & 0.66 & $1.0(0.8-1.2)$ & 0.67 \\
\hline Obesity & $1.1(0.8-1.5)$ & 0.62 & $1.0(0.8-1.3)$ & 0.91 \\
\hline Smoking * & $1.1(0.8-1.5)$ & 0.63 & $0.8(0.6-1.1)$ & 0.12 \\
\hline $\begin{array}{l}\text { Family history of myocardial } \\
\text { infarction * }\end{array}$ & $0.9(0.6-1.3)$ & 0.48 & $0.9(0.7-1.2)$ & 0.64 \\
\hline Stroke* & $0.5(0.1-2.0)$ & 0.32 & $0.5(0.2-1.3)$ & 0.14 \\
\hline Myocardial infarction * & $2.7(1.2-6.2)$ & 0.017 & $3.2(1.8-5.7)$ & $<0.0001$ \\
\hline Atrial fibrillation * & $0.9(0.4-2.2)$ & 0.88 & $1.0(0.5-1.8)$ & 0.90 \\
\hline
\end{tabular}




\begin{tabular}{|l|l|l|l|l|}
\hline Congestive heart failure * & $1.7(0.6-5.0)$ & 0.31 & $1.8(0.8-3.7)$ & 0.13 \\
\hline Coronary artery disease * & $0.8(0.3-1.7)$ & 0.51 & $0.7(0.4-1.2)$ & 0.17 \\
\hline Peripheral artery disease * & $0.5(0.2-1.3)$ & 0.15 & $0.8(0.4-1.4)$ & 0.4 \\
\hline
\end{tabular}

OR $=$ odds ratio, $95 \% \mathrm{Cl}=95 \%$ confidence interval; ${ }^{*}$ self-reported 
Table 4: Mean spherical equivalent in different posterior segment leisons in the German population-based Gutenberg Health Study (GHS), 2007-2012.

\begin{tabular}{|l|l|}
\hline Lesion & Mean (SD) spherical equivalent in dioptres \\
\hline Choroidal nevi & $-0.2(2.2)$ \\
\hline Drusen of the optic nerve head & $-0.4(2.2)$ \\
\hline Tilted discs & $-3.6(4.0)$ \\
\hline Chorioretinal scars suggestive of Toxoplasmosis & $-0.2(2.4)$ \\
\hline Retinitis pigmentosa & $-0.2(1.3)$ \\
\hline Persistent posterior hyaloid artery & $-0.3(0.3)$ \\
\hline
\end{tabular}

$\mathrm{SD}=$ standard deviation 
Table 5: Associations of tilted discs with ocular parameters and cardiovascular risk factors in the German population-based Gutenberg Health Study (GHS), 2007-2012.

\begin{tabular}{|l|l|l|}
\hline & OR (95\% $\mathbf{C I})$ & p-value \\
\hline Sex & $1.0(0.7-1.4)$ & 0.83 \\
\hline Age $[10 \mathrm{y}]$ & $0.9(0.8-1.0)$ & 0.16 \\
\hline IOP $[\mathrm{mmHg}]$ & $1.1(1.0-1.2)$ & $\mathbf{0 . 0 1 1}$ \\
\hline CCT $[\mu \mathrm{m}]$ & $1.0(1.0-1.0)$ & 0.69 \\
\hline Hypertension & $1.1(0.8-1.6)$ & 0.64 \\
\hline Diabetes & $1.5(0.8-2.8)$ & 0.2 \\
\hline Dyslipidemia & $0.9(0.6-1.3)$ & 0.65 \\
\hline Obesity & $0.8(0.5-1.2)$ & 0.27 \\
\hline Smoking & $0.4(0.3-0.7)$ & $\mathbf{0 . 0 0 2 2}$ \\
\hline Family history of Myocardial infarction & $0.9(0.6-1.5)$ & 0.74 \\
\hline Results & & \\
\hline
\end{tabular}

Results of the logistic regression model including all variables, results with p-values $<0.05$ in bold. $\mathrm{OR}=$ odds ratio, $95 \% \mathrm{CI}=95 \%$ confidence interval. 
Table 2: Prevalences of posterior segment lesions (absolute and weighted for the region of Mainz and Mainz-Bingen) in the German population-based Gutenberg Health Study (GHS), 2007-2012.

\begin{tabular}{|c|c|c|c|c|}
\hline & $\begin{array}{l}\text { Frequency and } \\
\text { Prevalence }\end{array}$ & Total & Men & Women \\
\hline \multirow[t]{2}{*}{ Choroidal nevi } & Absolute, n (\%) & $\begin{array}{l}287 \\
(2.5 \%, 2.2 \%- \\
2.8 \%)\end{array}$ & $\begin{array}{l}151 \\
(2.6 \%, 2.3 \%- \\
3.1 \%)\end{array}$ & $\begin{array}{l}136 \\
(2.4 \%, 2.0 \%- \\
2.8 \%)\end{array}$ \\
\hline & Weighted, n (\%) & $\begin{array}{l}281 \\
(2.4 \%, 2.1 \%- \\
2.7 \%)\end{array}$ & $\begin{array}{l}143 \\
(2.5 \%, 2.1 \%- \\
2.9 \%)\end{array}$ & $\begin{array}{l}138 \\
(2.3 \%, 2.0 \%- \\
2.8 \%)\end{array}$ \\
\hline \multirow[t]{2}{*}{$\begin{array}{l}\text { Drusen of the optic } \\
\text { nerve head }\end{array}$} & Absolute, n (\%) & $\begin{array}{l}22 \\
(0.2 \%, 0.1 \%- \\
0.3 \%)\end{array}$ & $\begin{array}{l}11 \\
(0.2 \%, 0.1 \%- \\
0.3 \%)\end{array}$ & $\begin{array}{l}11 \\
(0.2 \%, 0.1 \%-0.3 \%)\end{array}$ \\
\hline & Weighted, n (\%) & $\begin{array}{l}21 \\
(0.2 \%, 0.1 \%- \\
0.3 \%)\end{array}$ & $\begin{array}{l}10 \\
(0.2 \%, 0.1 \%- \\
0.3 \%)\end{array}$ & $\begin{array}{l}11 \\
(0.2 \%, 0.1 \%-0.3 \%)\end{array}$ \\
\hline \multirow[t]{2}{*}{ Tilted discs } & Absolute, n (\%) & $\begin{array}{l}192 \\
(1.5 \%, 1.3 \%- \\
1.7 \%)\end{array}$ & $\begin{array}{l}92 \\
(1.4 \%, 1.2 \%- \\
1.8 \%)\end{array}$ & $\begin{array}{l}100 \\
(1.6 \%, 1.3 \%-1.9 \%)\end{array}$ \\
\hline & Weighted, n (\%) & $\begin{array}{l}191 \\
(1.5 \%, 1.3 \%- \\
1.7 \%)\end{array}$ & $\begin{array}{l}87 \\
(1.4 \%, 1.1 \%- \\
1.7 \%)\end{array}$ & $\begin{array}{l}104 \\
(1.6 \%, 1.3 \%-2.0 \%)\end{array}$ \\
\hline \multirow[t]{2}{*}{$\begin{array}{l}\text { Chorioretinal scars } \\
\text { suggestive of } \\
\text { Toxoplasmosis }\end{array}$} & Absolute, n (\%) & $\begin{array}{l}22 \\
(0.2 \%, 0.1 \%- \\
0.3 \%)\end{array}$ & $\begin{array}{l}15 \\
(0.3 \%, 0.2 \%- \\
0.5 \%)\end{array}$ & $\begin{array}{l}7 \\
(0.1 \%, 0.1 \%-0.3 \%)\end{array}$ \\
\hline & Weighted, n (\%) & $\begin{array}{l}21.5 \\
(0.2 \%, 0.1 \%- \\
0.3 \%)\end{array}$ & $\begin{array}{l}14 \\
(0.2 \%, 0.1 \%- \\
0.4 \%)\end{array}$ & $\begin{array}{l}7.5 \\
(0.1 \%, 0.1 \%-0.3 \%)\end{array}$ \\
\hline Retinitis pigmentosa & Absolute, n (\%) & $6(<0.1 \%)$ & $4(<0.1 \%)$ & $2(<0.1 \%)$ \\
\hline
\end{tabular}




\begin{tabular}{|l|l|l|l|l|}
\hline & Weighted, $\mathrm{n}(\%)$ & $5(<0.1 \%)$ & $3(<0.1 \%)$ & $2(<0.1 \%)$ \\
\hline $\begin{array}{l}\text { Persistent hyaloid } \\
\text { artery }\end{array}$ & Absolute, $\mathrm{n}(\%)$ & $3(<0.1 \%)$ & $2(<0.1 \%)$ & $1(<0.1 \%)$ \\
\cline { 2 - 5 } & Weighted, n (\%) & $2(<0.1 \%)$ & $1(<0.1 \%)$ & $1(<0.1 \%)$ \\
\hline
\end{tabular}

${ }^{*} \mathrm{~N}$, prevalence in percentage with $95 \%$ confidence interval 